\title{
Frequent Self-Weighing and Visual Feedback for Weight Loss in Overweight Adults
}

\author{
Carly R. Pacanowski ${ }^{1,2}$ and David A. Levitsky ${ }^{1,2}$ \\ ${ }^{1}$ University of Minnesota Division of Epidemiology \& Community Health, 1300 S. 2nd Street, Suite 300, Minneapolis, MN 55454, USA \\ ${ }^{2}$ Cornell University Division of Nutritional Sciences, 112 Savage Hall, Ithaca, NY 14853, USA \\ Correspondence should be addressed to Carly R. Pacanowski; cpacanow@umn.edu
}

Received 23 October 2014; Revised 8 April 2015; Accepted 13 April 2015

Academic Editor: Francesco Saverio Papadia

Copyright (c) 2015 C. R. Pacanowski and D. A. Levitsky. This is an open access article distributed under the Creative Commons Attribution License, which permits unrestricted use, distribution, and reproduction in any medium, provided the original work is properly cited.

\begin{abstract}
Evidence has suggested that self-weighing may be beneficial for weight control in adults, but few studies have independently assessed the contribution of this behavior to weight loss. This study experimentally tested daily self-weighing and visual feedback (the Caloric Titration Method (CTM)) as a weight loss and weight loss maintenance intervention over 2 years. 162 overweight individuals were randomized to the CTM intervention or delayed treatment control group. In year 1, weight change was compared between groups, and in year 2, the control group started using the CTM while the intervention group continued using the CTM for maintenance. A significant difference in weight loss over the first year (CTM $n=70 ; 2.6 \pm 5.9 \mathrm{~kg}$ versus control $n=65 ; 0.5 \pm 4.4 \mathrm{~kg}, p=0.019)$ was qualified by a group $\times$ gender $\times$ time interaction $(p=0.002)$ such that men lost more weight using the CTM. In year 2 , the CTM group maintained their weight and the control group lost an amount similar to the intervention group in year 1 . Daily selfweighing and visual feedback facilitated a minimal amount of weight loss and maintenance of this loss. Future research investigating characteristics of those who benefit from this type of self-directed intervention is warranted.
\end{abstract}

\section{Introduction}

Several studies have included self-weighing as a component of behavioral weight loss interventions [1-10]. Because selfweighing is typically used with other techniques to promote weight loss, its effectiveness has not been thoroughly assessed independently. Early studies compared groups that differed only in self-weighing frequency and indicated that the behavior was not helpful for weight loss [3-7]. However, more recent evidence has suggested that frequent self-weighing may be beneficial for weight control, including weight loss, prevention of weight gain, and prevention of weight regain after loss ([1, 2, 8, 11-16]; reviews: $[17,18])$. The majority of this evidence, with the exception of Fujimoto et al. (1992) and Steinberg et al. (2013), is correlational making it inappropriate to infer causality regarding the role of self-weighing in weight control.

Isolating the effects of frequent self-weighing for weight loss in adults is important for the field of weight control. Despite evidence that increases in overweight and obesity may be decreasing in some categories of the population, the proportion of overweight and obese adults in the United States remains high [19]. A weight loss as small as $5 \%$ of body weight may improve health [20]. Because frequent selfweighing is both relatively affordable and not time consuming, it is an important method to test independently to produce sustained weight reduction. Moreover, it is a feasible technique for individual use to monitor progress, with or without the assistance of a healthcare professional.

This study tests the effectiveness of a simple and affordable behavioral technique, frequent self-weighing and visual feedback, termed the "Caloric Titration Method" or CTM for weight loss and maintenance of loss in overweight and obese adults over a two-year period. It was hypothesized that the intervention group, given tools to self-weigh and view visual feedback of their weight history, would lose more weight over a one-year period compared with a delayed control group. Additionally, it was hypothesized that the intervention group would maintain their weight loss during the second year of the trial due to continued weighing and weight feedback. 


\section{Methods}

2.1. Participants and Procedures. All study procedures were conducted after approval from the university institutional review board. One hundred and seventy-eight individuals responded to advertisements, soliciting adults interested in weight loss. Newspaper advertisements, email newsletters, and public service announcements described study eligibility criteria (i.e., potential participants should be $\geq 18$, be not pregnant or planning to become pregnant, not have diabetes, not have a current eating disorder or history of an eating disorder, and have a body mass index $(B M I) \geq 27.0 \mathrm{~kg} / \mathrm{m}^{2}$ ). Sixteen interested individuals did not meet the BMI cutoff and were invited to participate in a "weight maintenance" cohort; results are discussed elsewhere [21].

Interested individuals were sent a copy of the consent form before attending the initial meeting. They were randomly assigned to one of two groups (control or intervention) and offered to attend one of two sessions for either group, held on different days (to maximize attendance). Participants were not informed of their group assignment until the initial session to minimize control group dropout and were asked to voluntarily consent after the session.

The initial session was an educational presentation about evidence-based strategies for weight loss, with an emphasis on self-selection of strategies to meet individual needs. Making small changes, amounting to or averaging $100 \mathrm{kcal}$ deficits per day, was encouraged (e.g., skipping dessert a few times per week; using a meal replacement for lunch $3 \mathrm{x}$ a week; abstaining from snacking most days of the week). For more details on evidence-based strategies that were presented as options, see reference [22]. The only difference between control and intervention group initial sessions was that the intervention group session concluded with an explanation of the CTM intervention. Participants were provided with a typical bathroom scale (American Weigh Scales Model 330 LPW) and asked to weigh daily, under consistent circumstances, ideally, first thing in the morning, immediately after rising. They were also shown how to access a computer website (http://weightloss.human.cornell.edu/) where they were directed to register and enter their weight daily.

Control group participants were told that they would receive the intervention after one year. During this year, they were permitted to do anything they would normally do to lose weight. Intervention participants were permitted to do anything they wished to lose weight in addition to using the CTM. A goal of $10 \%$ weight loss in the first year was advised and then maintenance through continued weighing and recording in the second year.

After one year, participants randomized to the control group were provided with the CTM intervention-a body weight scale, instructions for setting up an account using the website, and the same informational handout. The audiorecorded educational session and explanation of how to use the CTM were available on the website. Participants in the intervention group were instructed to continue weighing themselves and entering their weight during year 2 of the trial and to maintain their weight loss or continue losing weight if they wished.
2.2. The Caloric Titration Method (CTM) Intervention. The CTM provides feedback of an individual's weight trends over time, as shown in Figure 1.

Weight loss is directed by small decrements, equivalent to $1 \%$ of starting body weight. Once 8 weight measurements have been entered, a green line appears $1 \%$ below the user's current weight to show the target weight. After the user reaches and maintains the target weight for 8 days, the green line is reduced by another $1 \%$ on the chart. This procedure continued until a maximum of $10 \%$ loss is reached, at which point weight maintenance is recommended. Intervention participants were directed to aim for the $10 \%$ weight loss goal over the first year, at which time they would maintain this loss during the second year of the trial. If participants did not enter a minimum of 3 weights per week, they were sent an email reminding them that they had not entered a sufficient number of weights for that week.

The CTM prompts slow weight loss in hope of producing a sustained weight loss. This method of small changes [23] and slow weight loss is contradictory to the idea that producing a rapid initial weight loss is more effective in producing and sustaining a weight loss $[24,25]$. The CTM allows people to test making small decrements in their energy intake such as a reduction in portion size, snacking, or desert eating by viewing feedback. By viewing the daily graph of their weight, they will know if the change they made is sufficient to produce a small decrement in their weight. Through this process of trial and error, each participant can discover their own methods for producing and sustaining a small energy deficit.

\subsection{Measures}

2.3.1. Body Weight. Participants were weighed using the same LifeSource Precision Scale, Model UC-321 at the initial session (baseline) and at 6, 12, and 24 months after baseline. Weight measurements were conducted in campus buildings or in a public location of the participant's choice.

2.3.2. Height. Height was self-reported at the initial session and at the 6-month weigh-in. If participants reported disparate heights, an average was taken. In addition, if participants visited a doctors' office and had their height measured, they were encouraged to contact the researchers with this information.

2.3.3. Demographic and Psychological Characteristics. Online questionnaires were administered at each of the time points listed above. The questionnaires assessed psychological and behavioral factors and experience using the CTM and are discussed elsewhere [26].

2.3.4. Analysis. Descriptive statistics and independent samples $t$-tests were performed; mixed models were used to analyze the data more extensively. All analyses followed an intent to treat strategy.

Some participants only have weight measurement values at baseline and 6 months due to nonresponse after repeated 


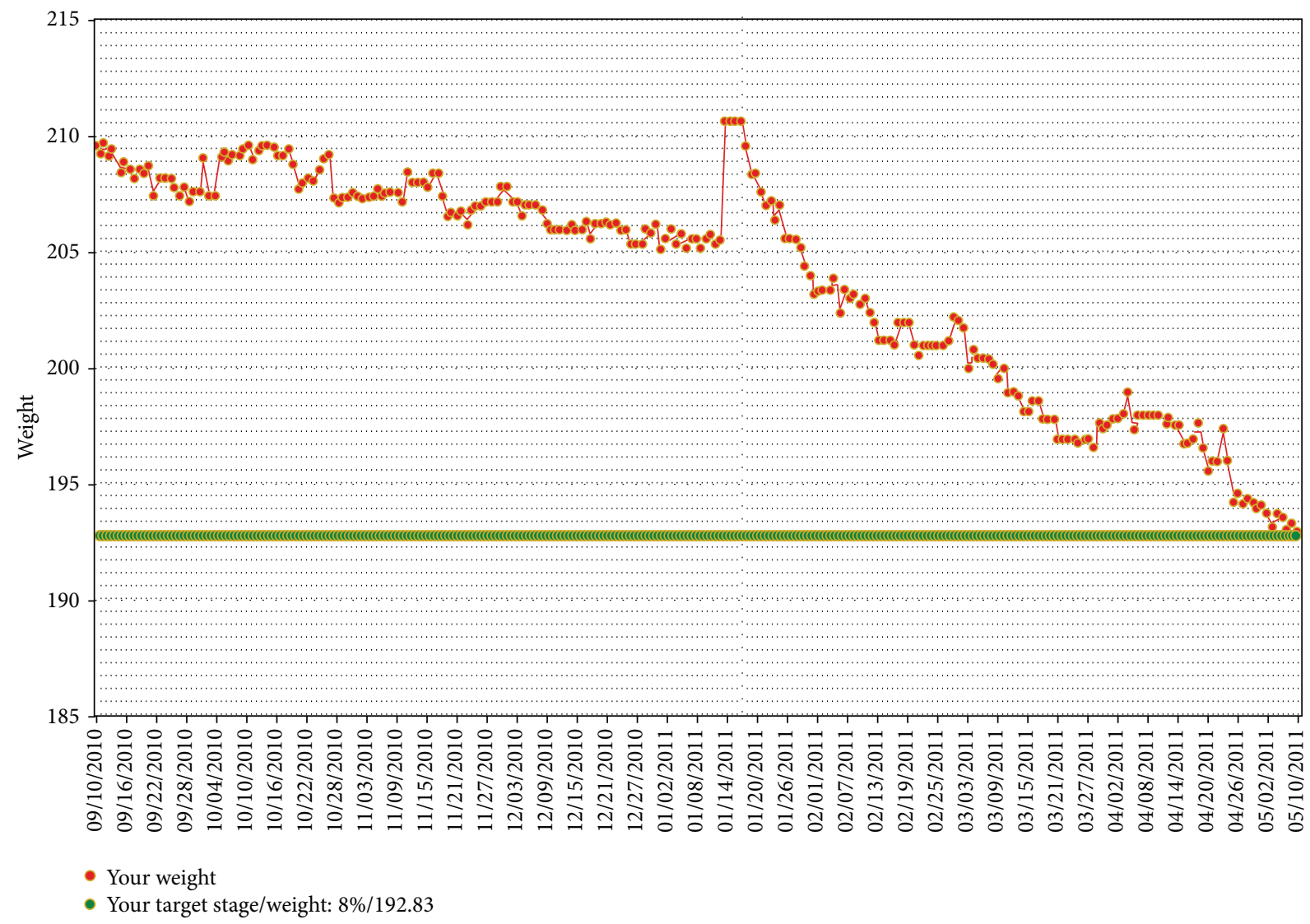

FIgURE 1: Sample view of CTM weight graph.

contacts from the research team. Because these individuals confirmed participation and were randomized, any information (e.g., survey or first weight) was included in analyses when possible. For example, in cases where the individual only attended the initial session, their initial session weight was carried forward, giving them a weight change over the first year of "0," a method known as last observation carried forward (LOCF). Analyses were repeated using a variable that excluded individuals with missing 12 -month weights and a variable that carried their baseline or 6-month weight forward.

All $t$-tests were 2-tailed because it was reasoned a priori that the results could go in either direction (the control group could lose more weight than the CTM intervention group or the CTM intervention group could lose more weight than the control group).

Mixed models allow for maximal usage of missing data; if an individual had only 2 data points for the first year, their data could be used without imputation. Specifically, a random intercept random slope model was employed, which computes a linear regression for each individual's weight trajectory over the specified time period, allowing for more accurate description of their weight trajectory. The mixed model included a main effect of treatment group, a main effect of time, and the interaction between time and treatment group. The interaction term answers the question "Did weight change differently according to group?" Time was analyzed as a continuous variable.

\section{Results}

Of the 162 participants who were randomized ( 88 to the CTM intervention group and 74 to the control group, resp.), 8 never attended an initial session and 4 contacted the researchers after being randomized to say that they did not meet inclusion criteria (e.g., had diabetes and did not notice that was an exclusion criterion). Chi-squared statistics did not reveal significant differences as to which group the no-shows were randomized.

3.1. Participant Characteristics. Table 1 displays baseline participant characteristics.

The sample had an average age of $46.6 \pm 9.8$ years and an average BMI of $33.5 \pm 5.1 \mathrm{~kg} / \mathrm{m}^{2}$ and had completed an average of $15.9 \pm 2.2$ years of education (range 12-19 years). The majority of participants (81.9\%) were female. Most participants self-identified as white; the racial/ethnic composition of the sample is presented in Table 1. There were no significant differences between the control and intervention group at baseline.

3.2. Year 1 Results. On average, more than 4 weights per week were entered into the CTM program. A significant difference 
TABLE 1: Baseline characteristics for total sample and by treatment group.

\begin{tabular}{|c|c|c|c|c|}
\hline \multicolumn{5}{|c|}{ Baseline characteristics } \\
\hline & Total & Control & $\begin{array}{c}\text { CTM } \\
\text { intervention }\end{array}$ & $p$ value diff. ${ }^{a}$ \\
\hline Age (years) & $\begin{array}{c}46.6 \pm 9.6^{\mathrm{b}} \\
(n=144)^{\mathrm{c}}\end{array}$ & $\begin{array}{c}48.2 \pm 9.9 \\
(n=66)\end{array}$ & $\begin{array}{c}45.3 \pm 9.6 \\
(n=77)\end{array}$ & 0.071 \\
\hline BMI $\left(\mathrm{kg} / \mathrm{m}^{2}\right)$ & $\begin{array}{r}33.5 \pm 5.0 \\
(n=148)\end{array}$ & $\begin{array}{c}33.7 \pm 5.1 \\
(n=68)\end{array}$ & $\begin{array}{c}33.4 \pm 5.1 \\
(n=81)\end{array}$ & 0.898 \\
\hline Body weight (kgs) & $\begin{array}{c}93.8 \pm 17.4 \\
(n=148)\end{array}$ & $\begin{array}{c}93.1 \pm 17.9 \\
(n=68)\end{array}$ & $\begin{array}{c}94.3 \pm 17.0 \\
(n=81)\end{array}$ & 0.690 \\
\hline Body weight (lbs) & $\begin{array}{c}206.7 \pm 38.3 \\
(n=149)\end{array}$ & $\begin{array}{c}205.3 \pm 39.5 \\
(n=68)\end{array}$ & $\begin{array}{c}207.8 \pm 37.4 \\
(n=81)\end{array}$ & 0.690 \\
\hline Height (in) & $\begin{array}{r}65.7 \pm 3.7 \\
(n=142)\end{array}$ & $\begin{array}{c}65.3 \pm 3.7 \\
(n=65)\end{array}$ & $\begin{array}{c}66.1 \pm 3.7 \\
(n=77)\end{array}$ & 0.199 \\
\hline Female $^{\mathrm{d}}(n, \%)$ & $122,81.9$ & $59,86.8$ & $63,77.8$ & 0.156 \\
\hline Education (years), highest level of education completed & $\begin{array}{r}15.9 \pm 2.2 \\
(n=146)\end{array}$ & $\begin{array}{c}16.0 \pm 2.2 \\
(n=67)\end{array}$ & $\begin{array}{c}15.8 \pm 2.2 \\
(n=79)\end{array}$ & 0.454 \\
\hline \multicolumn{5}{|l|}{ Ethnicity (number of participants) } \\
\hline American Indian & 3 & 2 & 1 & e \\
\hline Asian & 2 & 2 & 0 & \\
\hline African American & 6 & 3 & 3 & \\
\hline Hispanic & 1 & 1 & 0 & \\
\hline White & 144 & 65 & 79 & 0.696 \\
\hline Other & 2 & 0 & 2 & \\
\hline
\end{tabular}

in mean within subject weight loss was found between the control group $(n=65 ; 0.5 \pm 4.4$ kilograms $(\mathrm{kg}))$ and the CTM intervention group $(n=70 ; 2.6 \pm 5.9 \mathrm{~kg})$ over the first year $(p=0.019)$. Nonparametric tests (Mann-Whitney $U$ ) revealed very similar results $(p=0.02)$.

The difference in weight loss remained when employing the LOCF method for handling missing data. A significant difference in mean within subject weight loss was found between the control group $(n=67 ; 0.4 \pm 4.4 \mathrm{~kg})$ and the CTM intervention group $(n=81 ; 2.1 \pm 5.6 \mathrm{~kg})$ over the first year $(p=0.037)$.

The number of participants achieving $\geq 5 \%$ weight loss over the first year in the intervention group was $20(28.6 \%)$ and $7(10.8 \%)$ in the control group (chi-squared 2-sided, $p$ value $=0.01$ ). The number of participants achieving $\geq 10 \%$ weight loss over the first year in the intervention group was 6 $(8.6 \%)$ and $3(4.6 \%)$ in the control group (Fisher's exact test 2-sided, $p$ value $=0.50$ )

A mixed model analyzing weight change over the first year revealed a significant interaction between treatment group and time $(p=0.026)$. When comparing the linear weight trajectories between the intervention group and the control group, the slope of the line increases by $1.0 \mathrm{~kg}(95 \%$ CI [0.1-1.9]).
Exploratory analyses revealed that gender was influencing the difference in weight loss over the first year. Figure 2 graphs the mixed model's estimation of means by treatment group and gender at each time point and displays the significant three-way interaction between treatment group, gender, and time $(p=0.02)$.

The difference in baseline body weight in men randomized to the CTM intervention and control group was not significantly different $(p=0.314)$. Due to the possibility that outliers were driving the group by gender interaction, residual versus predicted values of the dependent variable, weight change over the first year, were plotted and appeared fairly evenly dispersed around the horizontal axis.

3.3. Year 2 Results. In year 2, participants in the control group were provided with the CTM intervention. This group's weight loss over year 2 was on average $1.9 \pm 5.7 \mathrm{~kg}(n=57)$. This loss was significantly different from zero $(p=0.013)$ but was not significantly different from the average loss of the CTM intervention group in year $1(2.6 \pm 5.9 \mathrm{~kg} ; n=70$; $p=0.524$ ).

In year 2, the goal for participants continuing in the CTM intervention group was maintenance. The average weight change was $0.1 \pm 4.8 \mathrm{~kg}$, a value not significantly different from zero $(p=0.929)$. 


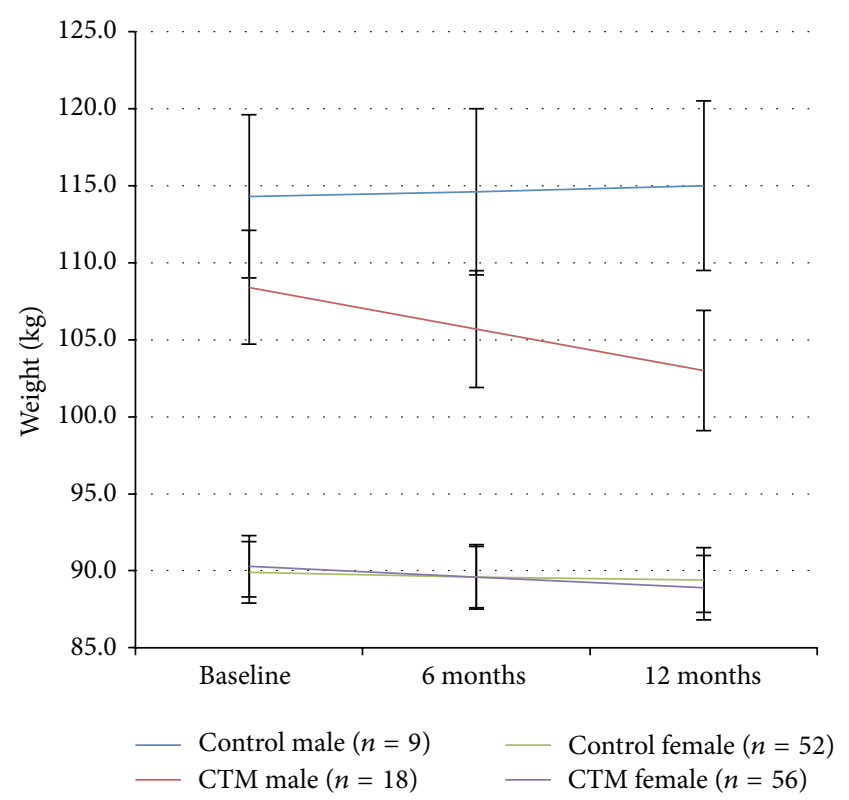

Figure 2: Body weight over time by treatment group and gender: year 1. Error bars are \pm 1 standard deviation of the estimated marginal mean for the mixed model.

Figure 3 displays change in weight over time by treatment group and gender using means from a random intercept model of weight trajectory between 12 and 24 months.

The males continuing to use the CTM intervention maintained their reduced weight, while the control males (given the intervention) lost weight-this loss was not statistically different from the amount lost by the males given the CTM intervention in the first year $(p=0.42)$. The females in the second year, on the other hand, showed no significant effect of using the CTM similar to the effect observed during the first year.

Though the goal of the CTM intervention group was to lose $10 \%$ of starting weight over one year, most of the participants did not reach this goal. Figure 4 shows the cumulative distribution of weight loss for participants using the CTM over one year, combining the first year of the intervention group with the second year of the delayed control group for a sample size of 119 .

The average weight loss was $2.5 \pm 5.7$ percent of starting body weight.

\section{Discussion}

The major finding of this study is that the use of frequent weighing accompanied by visual feedback of weight, without a prescribed diet or exercise plan, was effective in producing a small but sustainable weight loss in overweight males.

The amount of weight lost during the first year of the intervention was relatively small; intervention participants lost an average of $2.7 \pm 5.9$ percent of their body weight, while participants in the control group lost an average of

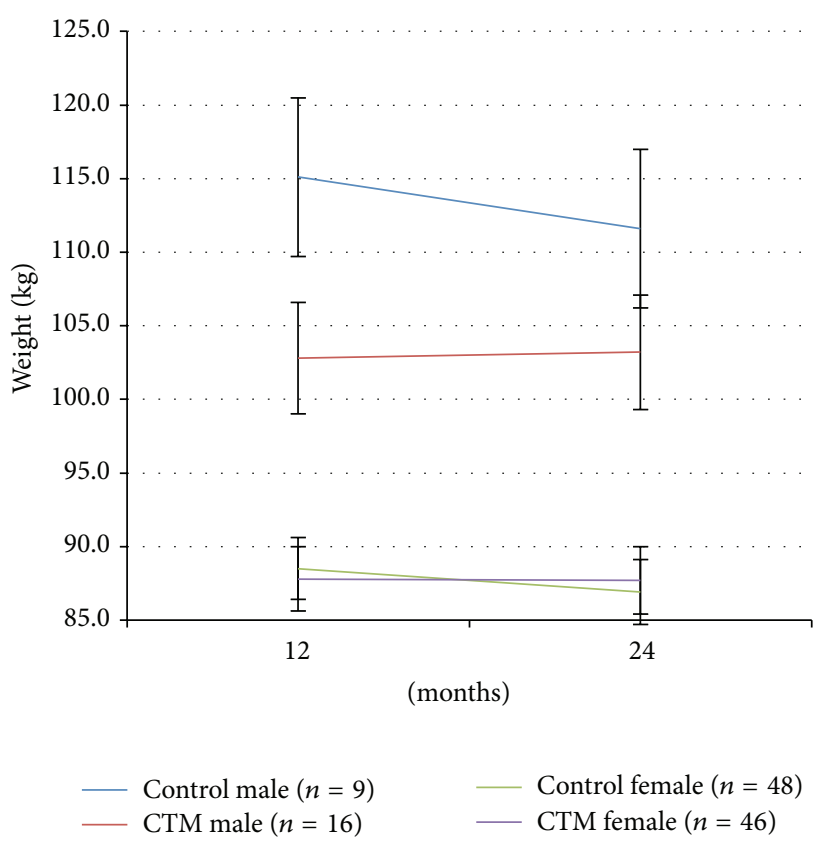

FIGURE 3: Body weight over time by treatment group and gender: year 2 . Error bars are \pm 1 standard deviation of the estimated marginal mean for the mixed model.

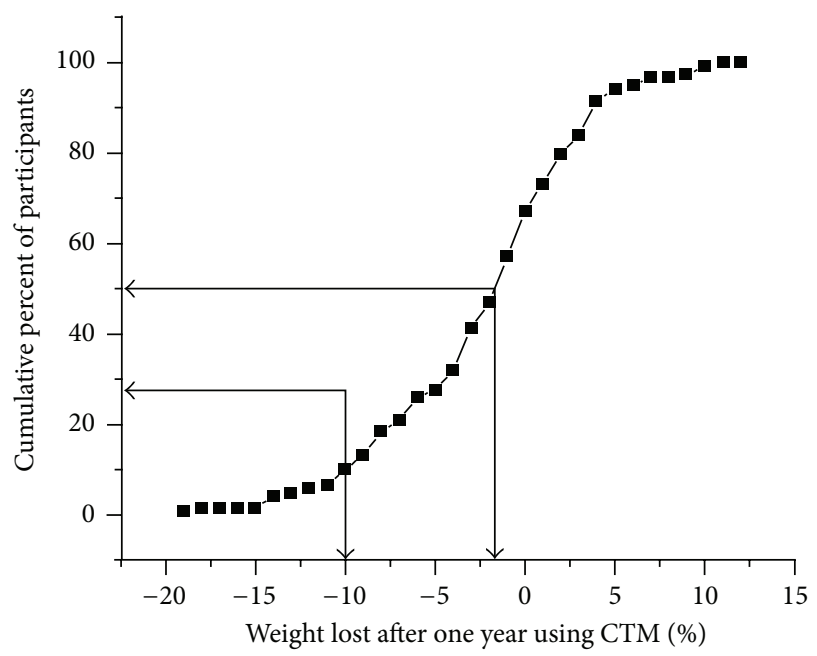

FIGURE 4: Cumulative distribution of weight loss after one year of CTM use.

$0.5 \pm 4.8$ percent of their body weight. A similar degree of weight loss was observed in the delayed treatment control group, who lost an average of $1.9 \pm 5.4$ percent of their starting weight over year 2 of the trial. For comparison with published results, over the first 6 months, intervention participants lost an average of $1.1 \pm 4.2$ percent of their body weight and control participants lost an average of $0.1 \pm 3.6$ percent of their body weight. Two studies reported, on average, greater than 6 percent of body weight lost after 6 months, using an intervention including self-weighing but also other education 
and behavioral components $[2,8]$. The amount of weight loss observed in this study over one year $(2.7 \pm 5.9$ percent $)$ was comparable to programs using internet based weight loss with minimal intensity (e.g., 1.1 percent weight loss at 1 year using a commercial online program in "Internet-Based Commercial Weight Loss Programs" section [27]).

For the first year of the study, exploratory analyses led to post hoc findings suggesting that the CTM helped to facilitate weight loss in men, but to a lesser degree, and not statistically significant in women. Counter to expectations, women in the control group lost weight during the trial, albeit a small amount. It is possible that the sample size was too small to detect a significant between-group effect or that this method was simply not effective beyond what women normally would do to lose weight. For males, the contrast is clearer-males in the control group gained weight over the first year while males in the experimental group lost weight.

Year 2 of the study provided data to support the hypothesis that after facilitating weight loss, the CTM would help individuals to maintain that loss. Table 2 shows the mean percent weight gain from the present study along with data from 44 groups collected from 12 published studies that tracked body weights for one year following weight loss. As is evident from this table, the maintenance of body weight following weight loss is rarely observed. The average amount of weight regain was $35.5 \%$ (95\% CI [20.91-50.16]) of the participant's weight measured at the end of the weight loss treatment. These data suggest that the use of the CTM, or other methods that utilize daily weighing, may play a greater role in the prevention of weight regain than in the production of a weight loss.

Principles of behaviorism underlie the tenants of the CTM: with weight information provided daily, adjustments can be made to intake or expenditure to control body weight. The feedback provided by the weight chart is theorized to reinforce behaviors that cause weight to move in the intended direction, allowing participants to make changes in their eating or activity that best fit their lifestyle. This kind of flexible restraint has been found to be more closely related to successful dieting than the conventional type of dieting [28].

The rationale for using slow weight loss, guided by $1 \%$ decrements, with the CTM is that people initially try several techniques to reduce their energy intake or increase their energy expenditure. All work in the short term, but sustaining a weight loss requires that the person finds those behavioral changes they can live with over a prolonged, if not indefinite, period of time.

4.1. Limitations and Contributions. This study has a number of limitations. Participants were self-selected individuals interested in losing weight. These individuals were members of a campus wellness organization suggesting that these people may have had a heightened concern about their health. Due to racial and ethnic homogeneity, generalizations about how the CTM may influence weight in diverse populations cannot be made from this study. Similarly, conclusions about different age ranges or stages in life (e.g., premenopausal versus postmenopausal) cannot be made. Also, only a small number $(n=6)$ of participants in the intervention group reached the suggested goal of $10 \%$ weight loss in the first year of the study. Information about personal weight loss goals and if these exceeded or were less than the researcher suggested $10 \%$ goal would have been helpful in providing information for why this goal was not met. It is possible that the self-directed nature of the CTM program only works for a small percentage of people to produce a $10 \%$ weight loss, while smaller losses (e.g., 2-3\%) are possible for a larger percentage of people. The most concerning limitation is that we are unable to separate the degree to which the CTM was the factor causing the weight change versus the fact that participants were cognizant of the study team's oversight. We tried to keep investigator involvement and participants' desire to please the investigator at a minimum; no rewards were provided or congratulatory remarks were sent as a rule when stage changes were made. Despite these efforts, for many participants, knowing that someone was watching them may have influenced study engagement and, therefore, weight loss over the course of the study.

Despite these limitations, this study makes a meaningful contribution to the existing work on weight control. This is the only weight loss study we are aware of that focuses its intervention uniquely on self-weighing (and visual feedback) without the addition of weight loss education lessons as comparable studies tend to use more of a comprehensive approach (e.g., [8]). Since the control group and experimental group received identical information about weight loss strategies at the initial session (with the exception of the description of the CTM) this factor can be ruled out as having contributed to the weight effects.

This study tested a low-cost and low-intensity intervention that can be disseminated easily through the internet. This type of program would be feasible for healthcare practitioners to carry out with a moderate number of patients, allowing them to allocate their time to those that require more support. From the patient's perspective, this would enable one to manage one's own weight while knowing that the process is being overseen. Most importantly, the small weight losses achieved with using the CTM were maintained during the second year of the study.

\section{Conclusion}

In a society that has seen body weights increasing for several decades, techniques to reduce weight, even minimally, and sustain this reduction are important. As little as $5 \%$ weight loss is clinically significant [29]. The intervention group in this study lost about half of this amount using the CTM intervention. Self-weighing and visual feedback may be a useful strategy combined with other techniques to promote healthful weight loss. 
TABLE 2: Comparison between present results and studies that have observed weight changes for one year following treatment.

\begin{tabular}{|c|c|c|}
\hline Study & Observation (subgroup) & Percent weight regained \\
\hline Present study & CTM & -0.85 \\
\hline Sherwood et al. [30] & Guided & 5.09 \\
\hline Richelsen et al. [31] & Orlistat & 5.09 \\
\hline Wing et al. [16] & Face to face & 6.50 \\
\hline Perri et al. [32] & Face-to-face extended care & 11.88 \\
\hline Perri et al. [32] & Telephone extended care & 12.77 \\
\hline Cussler et al. [33] & Internet & 13.21 \\
\hline Perri et al. [34] & Behavioral therapy + exercise + maintenance training & 13.54 \\
\hline Wing et al. [16] & Control & 16.13 \\
\hline Wing et al. [16] & Internet & 16.15 \\
\hline Sherwood et al. [30] & Self-guided & 16.93 \\
\hline Davidson et al. [35] & Orlistat-orlistat & 17.83 \\
\hline Perri et al. [34] & Problem-solving & 18.29 \\
\hline Cussler et al. [33] & Self-directed & 19.23 \\
\hline Perri et al. [34] & Behavioral therapy + maintenance training & 19.26 \\
\hline Sjöström et al. [36] & Orlistat-orlistat & 19.65 \\
\hline Richelsen et al. [31] & Placebo & 20.70 \\
\hline Harvey-Berino et al. [37] & In person & 21.69 \\
\hline Davidson et al. [35] & Orlistat-low dose & 24.58 \\
\hline Sjöström et al. [36] & Placebo-placebo & 25.74 \\
\hline Sjöström et al. [36] & Placebo-orlistat & 28.04 \\
\hline Perri et al. [34] & Relapse prevention training & 28.16 \\
\hline Davidson et al. [35] & Placebo & 33.53 \\
\hline Perri et al. [32] & Education & 35.24 \\
\hline Harvey-Berino et al. [37] & Internet & 36.23 \\
\hline Kramer et al. [38] & Control & 36.79 \\
\hline Kramer et al. [38] & Skills focused & 38.76 \\
\hline Sjöström et al. [36] & Orlistat-placebo & 41.53 \\
\hline Harvey-Berino et al. [37] & Minimum personal & 41.67 \\
\hline Stevens et al. [39] & All & 45.45 \\
\hline Kramer et al. [38] & Weight focused & 46.69 \\
\hline Stevens et al. [39] & White men & 47.27 \\
\hline Stevens et al. [39] & White men and women & 48.98 \\
\hline Stevens et al. [39] & All men & 50.98 \\
\hline Davidson et al. [35] & Orlistat-placebo & 51.42 \\
\hline Stevens et al. [39] & White women & 52.78 \\
\hline Perri et al. [40] & Behavioral therapy + exercise & 54.07 \\
\hline Perri et al. [34] & No further training & 60.88 \\
\hline Stevens et al. [39] & All women & 61.29 \\
\hline Perri et al. [40] & Behavioral therapy & 76.19 \\
\hline Stevens et al. [39] & Black women & 80.95 \\
\hline Stevens et al. [39] & All Blacks & 91.30 \\
\hline Stevens et al. [39] & Black men & 100.00 \\
\hline
\end{tabular}




\section{Conflict of Interests}

The authors have no conflict of interests with regard to this paper.

\section{Acknowledgment}

Carly R. Pacanowski is supported by NIH/NIDDK-Ruth L. Kirschstein National Research Service Award, Institutional Research Training Grant (T32-DK083250). The authors would like to thank Dr. Jennifer A. Linde for her assistance in editing and paring down the paper.

\section{References}

[1] K. Fujimoto, T. Sakata, H. Etou et al., "Charting of daily weight pattern reinforces maintenance of weight reduction in moderately obese patients," The American Journal of the Medical Sciences, vol. 303, no. 3, pp. 145-150, 1992.

[2] J. Gokee-Larose, A. A. Gorin, and R. R. Wing, "Behavioral self-regulation for weight loss in young adults: a randomized controlled trial," International Journal of Behavioral Nutrition and Physical Activity, vol. 6, no. 1, p. 10, 2009.

[3] C. L. Heckerman, K. D. Brownell, and R. J. Westlake, "Self and external monitoring of weight," Psychological Reports, vol. 43, no. 2, pp. 375-378, 1978.

[4] M. J. Mahoney, N. G. M. Moura, and T. C. Wade, "Relative efficacy of self-reward, self-punishment, and self-monitoring techniques for weight loss," Journal of Consulting and Clinical Psychology, vol. 40, no. 3, pp. 404-407, 1973.

[5] M. J. Mahoney, "Self reward and self monitoring techniques for weight control," Behavior Therapy, vol. 5, no. 1, pp. 48-57, 1974.

[6] R. G. Romanczyk, D. A. Tracey, G. T. Wilson, and G. L. Thorpe, "Behavioral techniques in the treatment of obesity: a comparative analysis," Behaviour Research and Therapy, vol. 11, no. 4, pp. 629-640, 1973.

[7] R. G. Romanczyk, "Self-monitoring in the treatment of obesity: parameters of reactivity," Behavior Therapy, vol. 5, no. 4, pp. 531540, 1974.

[8] D. M. Steinberg, D. F. Tate, G. G. Bennett, S. Ennett, C. SamuelHodge, and D. S. Ward, "The efficacy of a daily self-weighing weight loss intervention using smart scales and e-mail," Obesity, vol. 21, no. 9, pp. 1789-1797, 2013.

[9] R. B. Stuart, "Behavioral control of overeating," Behaviour Research and Therapy, vol. 5, no. 4, pp. 357-365, 1967.

[10] C. D. Madigan, K. Jolly, A. L. Lewis, P. Aveyard, and A. J. Daley, "A randomised controlled trial of the effectiveness of selfweighing as a weight loss intervention," International Journal of Behavioral Nutrition and Physical Activity, vol. 11, no. 1, p. 125, 2014.

[11] M. L. Butryn, S. Phelan, J. O. Hill, and R. R. Wing, "Consistent self-monitoring of weight: a key component of successful weight loss maintenance," Obesity, vol. 15, no. 12, pp. 3091-3096, 2007.

[12] R. W. Jeffery and S. A. French, "Preventing weight gain in adults: design, methods and one year results from the Pound of Prevention study," International Journal of Obesity, vol. 21, no. 6, pp. 457-464, 1997.

[13] R. W. Jeffery and S. A. French, "Preventing weight gain in adults: the pound of prevention study," American Journal of Public Health, vol. 89, no. 5, pp. 747-751, 1999.
[14] M. L. Klem, R. R. Wing, M. T. McGuire, H. M. Seagle, and J. O. Hill, "A descriptive study of individuals successful at longterm maintenance of substantial weight loss," American Journal of Clinical Nutrition, vol. 66, no. 2, pp. 239-246, 1997.

[15] J. A. Linde, R. W. Jeffery, S. A. French, N. P. Pronk, and R. G. Boyle, "Self-weighing in weight gain prevention and weight loss trials," Annals of Behavioral Medicine, vol. 30, no. 3, pp. 210-216, 2005.

[16] R. R. Wing, D. F. Tate, A. A. Gorin, H. A. Raynor, and J. L. Fava, "A self-regulation program for maintenance of weight loss," The New England Journal of Medicine, vol. 355, no. 15, pp. 1563-1571, 2006.

[17] C. R. Pacanowski, F. Bertz, and D. A. Levitsky, "Daily selfweighing to control body weight in adults: a critical review of the literature," SAGE Open, vol. 4, no. 4, 2014.

[18] Y. Zheng, M. L. Klem, S. M. Sereika, C. A. Danford, L. J. Ewing, and L. E. Burke, "Self-weighing in weight management: a systematic literature review," Obesity, vol. 23, no. 2, pp. 256265, 2015.

[19] K. M. Flegal, D. Carroll, B. K. Kit, and C. L. Ogden, "Prevalence of obesity and trends in the distribution of body mass index among US adults, 1999-2010," Journal of the American Medical Association, vol. 307, no. 5, pp. 491-497, 2012.

[20] G. Blackburn, "Effect of degree of weight loss on health benefits," Obesity Research, vol. 3, supplement 2, pp. 211S-216S, 1995.

[21] D. A. Levitsky, J. Garay, M. Nausbaum, L. Neighbors, and D. M. DellaValle, "Monitoring weight daily blocks the freshman weight gain: a model for combating the epidemic of obesity," International Journal of Obesity, vol. 30, no. 6, pp. 1003-1010, 2006.

[22] D. A. Levitsky, "The non-regulation of food intake in humans: hope for reversing the epidemic of obesity," Physiology and Behavior, vol. 86, no. 5, pp. 623-632, 2005.

[23] J. O. Hill, H. R. Wyatt, G. W. Reed, and J. C. Peters, "Obesity and the environment: where do we go from here?" Science, vol. 299, no. 5608, pp. 853-855, 2003.

[24] K. Elfhag and S. Rössner, "Initial weight loss is the best predictor for success in obesity treatment and sociodemographic liabilities increase risk for drop-out," Patient Education and Counseling, vol. 79, no. 3, pp. 361-366, 2010.

[25] A. Astrup and S. Rössner, "Lessons from obesity management programmes: greater initial weight loss improves long-term maintenance," Obesity Reviews, vol. 1, no. 1, pp. 17-19, 2000.

[26] C. R. Pacanowski, Effects of Self-Weighing and Visual Feedback on Weight Control in Adults, Cornell University, 2013.

[27] A. G. Tsai and T. A. Wadden, "Systematic review: an evaluation of major commercial weight loss programs in the United States," Annals of Internal Medicine, vol. 142, no. 1, pp. 56-66, 2005.

[28] K. Elfhag and S. Rössner, "Who succeeds in maintaining weight loss? A conceptual review of factors associated with weight loss maintenance and weight regain," Obesity Reviews, vol. 6, no. 1, pp. 67-85, 2005.

[29] DNPAO and CDC, Healthy Weight: Losing Weight, Division of Nutrition, Physical Activity, and Obesity (DNPAO), Centers for Disease Control and Prevention(CDC), 2011, http://www.cdc. gov/HEALTHYWEIGHT/LOSING_WEIGHT/INDEX.HTML.

[30] N. E. Sherwood, A. L. Crain, B. C. Martinson et al., "Enhancing long-term weight loss maintenance: 2 year results from the Keep It Off randomized controlled trial," Preventive Medicine, vol. 56, no. 3-4, pp. 171-177, 2013. 
[31] B. Richelsen, S. Tonstad, S. Rössner et al., "Effect of orlistat on weight regain and cardiovascular risk factors following a very-low-energy diet in abdominally obese patients: a 3-year randomized, placebo-controlled study," Diabetes Care, vol. 30, no. 1, pp. 27-32, 2007.

[32] M. G. Perri, M. C. Limacher, P. E. Durning et al., "Extendedcare programs for weight management in rural communities: the treatment of obesity in underserved rural settings (TOURS) randomized trial," Archives of Internal Medicine, vol. 168, no. 21, pp. 2347-2354, 2008.

[33] E. C. Cussler, P. J. Teixeira, S. B. Going et al., "Maintenance of weight loss in overweight middle-aged women through the internet," Obesity, vol. 16, no. 5, pp. 1052-1060, 2008.

[34] M. G. Perri, A. M. Nezu, W. F. McKelvey, R. L. Shermer, D. A. Renjilian, and B. J. Viegener, "Relapse prevention training and problem-solving therapy in the long-term management of obesity," Journal of Consulting and Clinical Psychology, vol. 69, no. 4, pp. 722-726, 2001.

[35] M. H. Davidson, J. Hauptman, M. DiGirolamo et al., "Weight control and risk factor reduction in obese subjects treated for 2 years with orlistat: a randomized controlled trial," The Journal of the American Medical Association, vol. 281, no. 3, pp. 235-242, 1999.

[36] L. Sjöström, A. Rissanen, T. Andersen et al., "Randomised placebo-controlled trial of orlistat for weight loss and prevention of weight regain in obese patients," The Lancet, vol. 352, no. 9123, pp. 167-172, 1998.

[37] J. Harvey-Berino, S. Pintauro, P. Buzzell, and E. C. Gold, "Effect of internet support on the long-term maintenance of weight loss," Obesity Research, vol. 12, no. 2, pp. 320-329, 2004.

[38] F. M. Kramer, R. W. Jeffery, M. K. Snell, and J. L. Forster, "Maintenance of successful weight loss over 1 year: effects of financial contracts for weight maintenance or participation in skills training," Behavior Therapy, vol. 17, no. 3, pp. 295-301, 1986.

[39] V. J. Stevens, E. Obarzanek, N. R. Cook et al., "Long-term weight loss and changes in blood pressure: results of the trials of hypertension prevention, phase II," Annals of Internal Medicine, vol. 134, no. 1, pp. 1-11, 2001.

[40] M. G. Perri, W. G. McAdoo, D. A. McAllister, J. B. Lauer, and D. Z. Yancey, "Enhancing the efficacy of behavior therapy for obesity: effects of aerobic exercise and a multicomponent maintenance program," Journal of Consulting and Clinical Psychology, vol. 54, no. 5, pp. 670-675, 1986. 


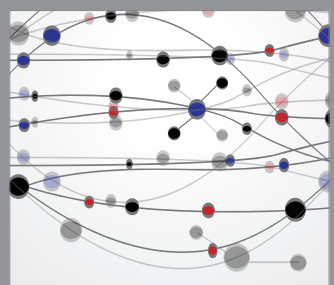

The Scientific World Journal
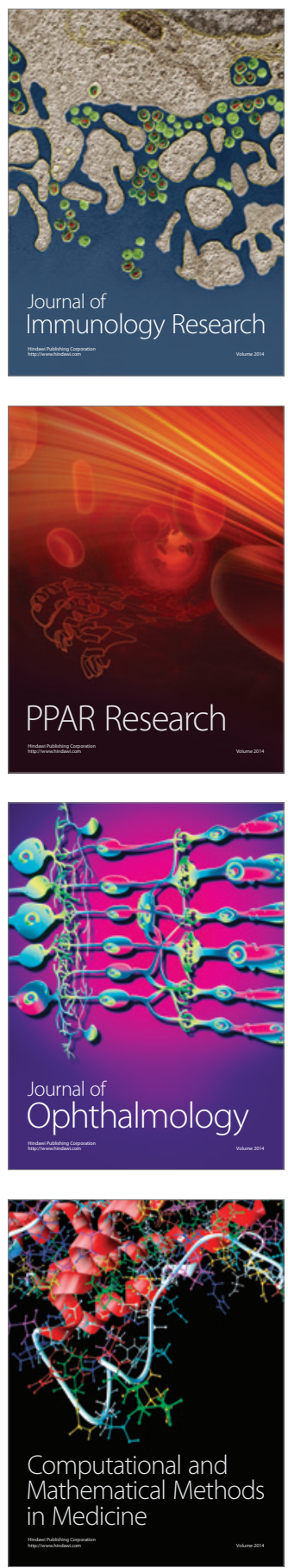

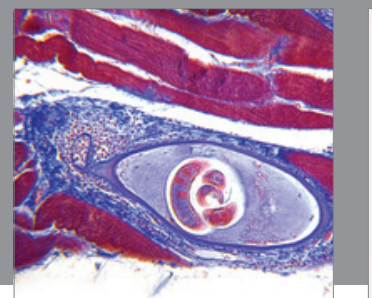

Gastroenterology

Research and Practice
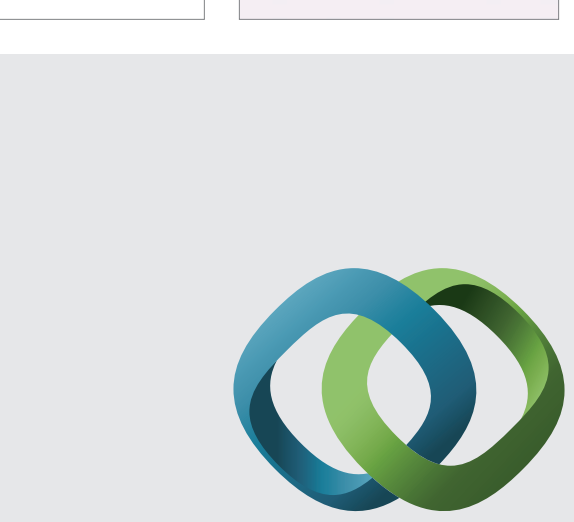

\section{Hindawi}

Submit your manuscripts at

http://www.hindawi.com
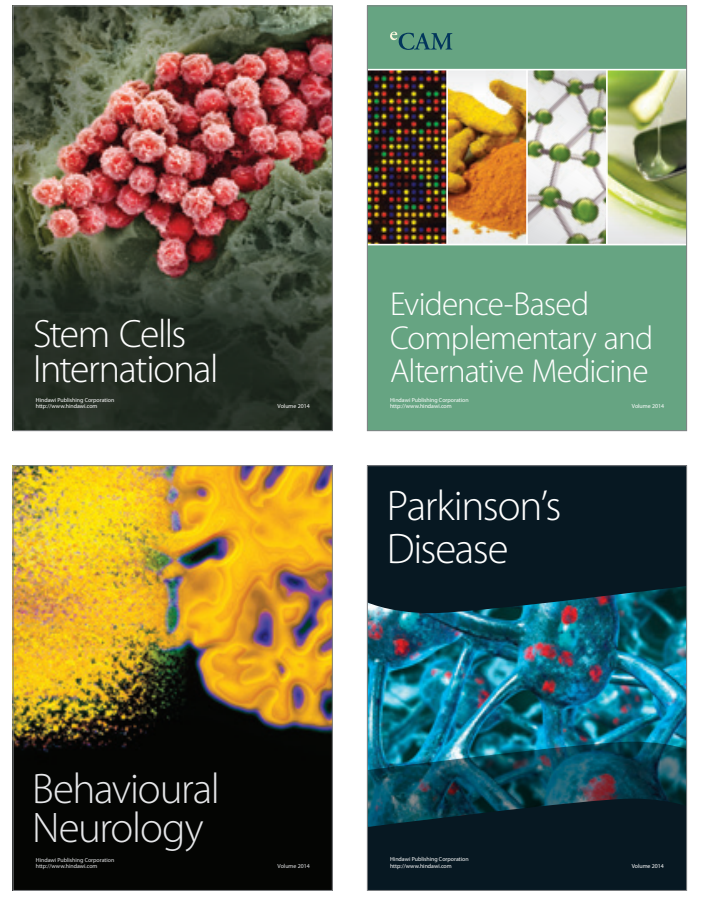
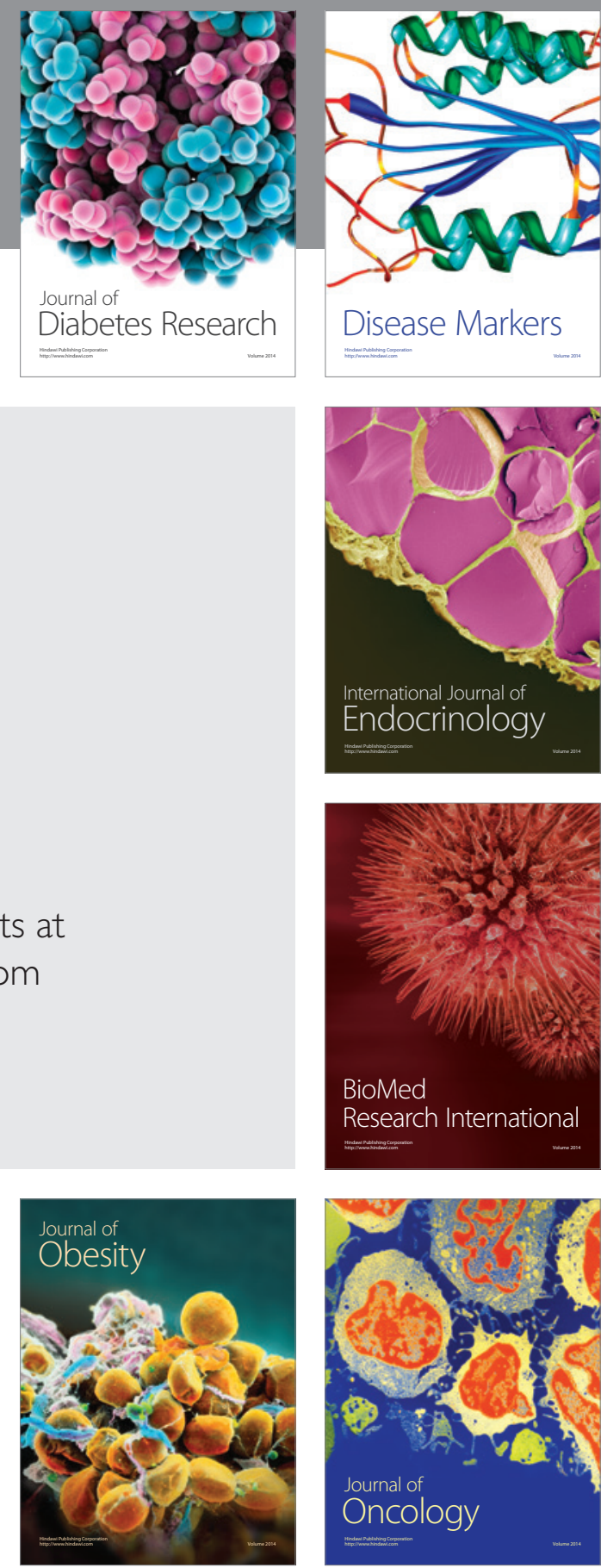

Disease Markers
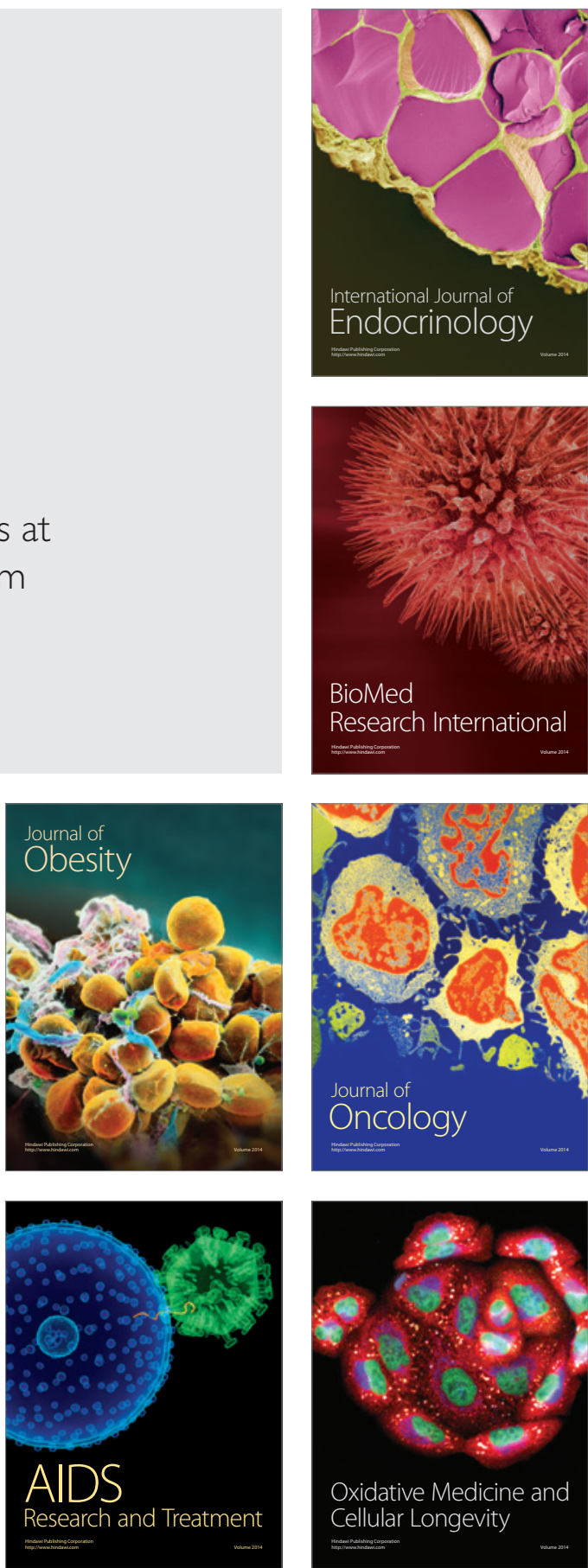